\title{
New Strategies and Approaches of Teaching Dynamic Assessment via Using Reading Comprehension to ESL/EFL Young University Learners
}

\author{
Rasool Hajizadeh \\ Islamic Azad University, Firoozabad Branch, Iran
}

\author{
Ali Reza Ahmadi \\ Shiraz University, Iran
}

\begin{abstract}
A procedure that attempts to modify performance, via examiner assistance, in an effort to understand learning potential, is called DA (dynamic assessment). DA stresses the need for unifying assessment and instruction. So, the teaching of DA in classroom requires strategies and approaches which can account for the distinctive meaningful features of it. Moreover, in ESL (English as a second language) and EFL (English as a foreign language) learning situations, the instructors require taking into consideration that the students are non-native speakers of English. Thus, the study and teaching of DA may involve an approach to texts as linguistic resources as well as cultural artifacts. Theoretically, DA posits a qualitatively different way of thinking about assessment from how it is traditionally understood by classroom teachers and researchers. The ZPD (zone of proximal development) by Vygotsky's research into the development of cognitive functions reveals that process is not a matter of innate abilities growing into a mature state but that it is the emergence of new ways of thinking, acting, and being that result from an individual's engagement in activities where learners are supported by cultural artifacts and by interactions with others. In this way, the social environment is not merely the stage on which development plays out; it is, in fact, the driving force of development. Initially, the teaching of DA should be concerned with enabling students to experience it, and later to enable them to describe and eventually account for the experience by making critical comments. The definition of DA and the style of presentation and the teaching of it should be concerned with students to experience measurement, and later to enable them to describe and eventually account for the experience by making critical comments. Encouraging debates and discussion on major issues of the text can be initiated by focusing on the fundamental elements of the DA teaching using several tips related to DA. Finally, we need to find out more about the ways in which tests and other assessments are used. Only through the systematic exploration of such questions will it eventually be possible to improve the quality of teaching DA data that language assessments provide. Relatively, this pedagogical approach has come to be known as DA. So, the focus of this paper is on the implementation of DA materials and texts in reading comprehension in ESL/EFL young English learners in classroom setting (Retrieved from http:// www.finchpark.com/afe/w.htm).
\end{abstract}

Keywords: DA (dynamic assessment), reading comprehension in ESL (English as a second language)/EFL (English as a foreign language), sociocultural theory of mind, teaching DA, ZPD (zone of proximal development), young learners

Rasool Hajizadeh, Islamic Azad University.

Ali Reza Ahmadi, Shiraz University. 


\section{Introduction}

Unfortunately, it seems that one of the most exhausting experience and frustrating parts of any educational course is the assessment issue. Poehner (2008) declared that "Students frequently echo this frustration when they are required to undergo regular assessment in order to demonstrate mastery of content or competency to pass to the next level of instruction" (p. 3). Researchers can also make the situation even harder when they raise the rerun question of "Why do we assess our students?" The reality is that assessment is most fully looked at as an information-gathering tool (Bailey, 1996). Restricting the function of assessment as only the data collecting tool not only causes to division between teaching, learning, and assessment, but puts assessment in direct opposition to instruction. One possible way to combine the two into distinctive as well as related fields is the development of DA (dynamic assessment) through reading comprehension materials and texts that make learning an easy and meaningful grasp. This reunification happens only when the researchers integrate a mediation phase into our assessment (Lidz \& Gindis, 2003). This view is in line with the approach to assessment and instruction defined in the SCT (Sociocultural Theory of Mind), as developed by the Russian psychologist Vygotsky and his followers about 80 years ago (Poehner, 2008).

Williams and Burden (1997) narrated that SCT is part of a larger paradigm that is called constructivism. There are two names which are collaborated with constructivism that are known as Piaget and Vygotsky. They disagreed mostly in the degree to which they value the role of social context in the development of language. Piaget stresses that language grows as a result of progressive growth of general intellectual skills (Woolfolk, 2004). Thus, it is possible to say that Piaget theory is a developmental one. However, Vygotsky proposed an alternative to Piaget's stages of cognitive development. Vygotsky's Sociocultural Theory of Development is at present an influential factor in education (Woolfolk, 2004). Vygotsky maintains that the primacy of social constructivist theory in social interaction is the motivational stimulus in language development. By the way, social constructivist theory, according to Nyikos and Hashimoto (1997), is mostly applied to address the learning through social interaction as described by ZPD which is taken into account as the distance between a child's actual cognitive employment and the level of potential development via mediation or scaffolding. So, under collaborative condition students reveal certain emergent functions which have not been yet fully internalized, or which have not been part of ZPD (Zone of Actual Development) (Kouzlin \& Grab, 2002). These are the functions that belong to ZPD.

Principle of Vygotsky's theory was also considered as the relationship between the development of thought and language. Vygotsky's theory regards language first as social communication which will step by step be promoting both language and cognition. This assumption comprises the fundamental part of social constructivist theory that puts its emphasize on the importance of socio-cultural factors in understanding what occurs in society and constructing knowledge based on interaction (Kumaravadivelu, 2006). It is assumed that if we are to apply social constructivist theory to our ESL (English as a second language)/EFL (English as a foreign language) teaching setting, the evaluation of the students in these settings also needs a change that should be appropriately redesigned. As Dixon and Krauss (1996) pointed out in ZPD was a dynamic working model because it both guides and evolves through the social interactions that take place during the course of learning activity. If this is the case, then we should think of a new model in order to measure the level of development of students in such dynamic context. The new model should be DA reading comprehension which is a proposal for measurement in such contexts that makes learning as easy as possible. They state that DA 
which is a recent development can be considered as an interactive approach to psycho educational assessment that pursues a test-intervene-retest format, focusing on learning processes and modifiability, and provides the possibility of direct linkage between assessment and intervention.

The interactional and reciprocal ties as well as the collaboration of DA and language teaching through reading comprehension have been the subject of interest to many foreign language teaching researchers, especially in the 20th century. Using DA as a vehicle for the teaching of a second or foreign language has proved very beneficial to the EFL and ESL students' learning experience. In educational contexts, this means that assessment-understanding pronominal learners' abilities, and instruction—supporting learner development, are dialectically integrated activities. This pedagogical approach has come to be known as DA. By the way, the task is not only concerned with the potential relevance of assessment to teaching and learning but conceptualizes their relationship in a manner that differs both epistemologically and ontologically from the perspectives that have come to dominate language studies in the world Poehner (2008).

Notable researchers such as Poehner (2008) and Van der Veer and Valsiner (1991) have all attested to the effectiveness of the implementation of DA in the language class. Teachers must emphasize on DA reading comprehension as a fundamental language skill that requires a complex acquisition process which can account for the way that learners comprehend what they obtain about DA. Many researchers and educators have made untiring attempts to find more efficient ways of enabling the learners to become more proficient DA learner. Therefore, a good number of ESL/EFL experts do agree that content knowledge is an important factor in the learning process of DA comprehension (Poehner, 2008; Van der Veer \& Valsiner, 1991). A valuable source of knowledge is, undoubtedly, DA texts, more appropriately for reading comprehension purposes. Using the DA materials and texts in order to enhance students' reading proficiency has another privilege for learners. DA is a compact accessible genre in which much is left unsaid in order for the reader to draw implications. Therefore, it makes students sensitive to the hidden and implied meaning. While in reading DA material students learn to read the lines and decode the meaning in reading comprehensions which are related to DA, they learn to read between the lines. Regarding the issue of DA organization, Arens, Swaffar, and Byrnes (1991) observed that "Students have greater success with texts that convince, inform, and persuade texts with rhetorical illocution - than they do with readings that are purely descriptive” (p. 115).

Indeed, DA as a multi-dimensional accessible genre can be profitably used in the acquisition of various language skills. DA's distinctive features, i.e., its brevity, modernity, and variety make it appealing and interesting to language learners. When the DA reading comprehension material is chosen based on the students' level of English proficiency, it can offer them adequate linguistic, intellectual, and emotional involvement and enrich their learning experience (Arens, Swaffar, \& Byrnes, 1991). Thus, this paper proposes that the dynamic assessment can provide ESL/EFL learners with a suitable study resource which is both delightful and instructive to improve their linguistic proficiency and reading comprehension. Consequently, the researchers aim to put forward a variety of strategies to make the teaching of DA enjoyable and academically enriching experience in aiding reading comprehension. These strategies include the design and implementation of motivation building techniques which facilitate overall reading comprehension, listening and spoken skills, and cultural orientation. And teachers should know that DA has direct application to the context of classroom assessment and instruction. Measuring responsiveness of an individual's performance to feedback has long been viewed as an alternative to traditional ability assessment. DA has been suggested to teachers as a means to enhance ESL/EFL performance by reading comprehension skill. 


\section{Discussion}

Using DA in the language classroom leads the learners to become better readers. Among the material forms, indeed, the texts which are related to DA are an engaging and exiting phenomena and can therefore be utilized for language learning purposes. Teachers should almost provide all modern DA reading materials that have the following unique characteristics which make them especially suitable to be used in reading comprehension classes: universality, non-triviality, personal relevance, variety, interest, economy, suggestive power, and ambiguity; moreover, each learner's interpretation has validity and an almost infinite fund of interactive discussion is guaranteed.

The DA reading comprehension materials create the tension necessary for a genuine exchange of ideas in class discussion. In addition, the using of these materials pushes the students out of a passive reading state into a personal connection with the text and then beyond, extending the connection to other texts and to the world outside of school. Closely related to the issue of implied meaning, Kumaravadivelu (2006) argued that there are two processes through which proficient readers figure out the meaning of a text. One is what he terms "bottom-up process" and the other he calls "top-down process". The bottom-up process is when the reader decodes the individual elements of the text to build a total meaning; however, in the top-down process the reader starts with forming hypotheses and making predictions. It is obvious that these two strategies are used simultaneously by a successful reader. With regard to the above argument, the advantage of using DA materials rather than a non-DA text is that some pre-reading activities which can be nicely applied to it (such as the discussion of the topic and DA structure) are very useful in facilitating the readers' top-down process. The legitimate application of usage of DA structure offers certain advantages for material design for ESL students since this genre includes short DA textual material to be satisfactorily handled in a one or limited teaching sessions by experienced teachers who are fully accounted by DA (Poehner, 2008).

\section{Text Selection}

The issue of text selection is a very significant one in using DA in general in language classes. Basically, DA reading comprehension materials are more suitable for students with a high level of language proficiency. Regarding DA materials, apart from the reader's linguistic proficiency, text difficulty depends on text's characteristics and the reader's DA competence. DA competence can be achieved through repeated exposure to its materials. However, regarding the text's features, careful attention should be paid to the structure of the text. It is generally preferred to choose texts with straightforward structures (Poehner, 2008).

Generally, the more confident choice concerning a suitable text for ESL/EFL learners may be the short definitions of DA which are more contemporary and short enough to be discussed in one or two teaching sessions. The linguistic aspects of the text should concern the language, style and diction, appropriate to the level of our students; Kumaravadivelu (2006) proposed that the text should sufficiently challenging without being so difficult as to be demotivating; it should be within the students' grasp, in terms of their linguistic, intellectual, and emotional capacities. Furthermore, reading a whole, unabridged, and non-simplified DA text could give the students a sense of accomplishment. Therefore, it will be encouraging when students are psychologically satisfied that they have read the very words of a great writer.

\section{Procedures and Strategies}

A systematic teaching strategy for DA can include the following stages:

(1) Pre-reading activities: to provide students with vocabulary exercises related to DA and cultural 
background;

(2) In-class oral reading: to improve listening and spoken abilities;

(3) Textual analysis and group work: to improve reading comprehension and communicative skills;

(4) Post-reading assignments: to establish the acquired knowledge and improve written skills as well.

Keeping in mind that the comprehension of the text is the central focus of the DA reading materials, as

Richard A. Raschio clarifies, the teacher must pay attention to the nonlinear process of the skill of reading. For each DA reading comprehension material, a number of tasks can be designed to cover the basic language skills required for an efficient reading comprehension. These tasks may include vocabulary work, reading comprehension questions, oral presentation of the text, in-class discussion, and interpretation, and finally follow-up tasks which can take the form of written responses or keep a journal (Kumaravadivelu, 2006).

Pre-reading activities: Vocabulary work. One vital issue concerning preliminary comprehension involves the task of overcoming the vocabulary presented by the text. Research studies have confirmed that the comprehension of reading passages which might present linguistic difficulties can be facilitated by appropriate pre-reading tasks. One aspect of the reading material is the vocabulary work. Students can be required to identify the new vocabulary in the text. The teacher can work together with the students to make a vocabulary list which includes new and targeted vocabulary list. The list can, then, be discussed in class. Students can form groups and work on portions of the list to find their meanings, both denotative and connotative. Since unfamiliar vocabulary will usually interfere with the students' comprehension and may be demotivating them to finish the text, such a list can be very useful.

Pre-reading the vocabulary items can also be used to facilitate the introduction of the necessary cultural background and even refer to thematic features of DA. However, the real vocabulary task occurs when students try to use these words in the textual context. A related and accompanying activity can be preparing a brief cloze-type exercise to encourage the students to guess the meaning from the context. In selecting and making the final vocabulary list, items which contain vital or emotional clues should be chosen.

In-class oral reading: Comprehension work. In the second stage, students focus on smaller units of the text. At the third stage, the teacher may activate the students' initial response to the text and finally in the fourth stage the teacher can introduce the formal features of DA materials and the texts. During the reading process, the teacher can help students prepare questions which can ultimately lead to the overall understanding of the text and thus facilitate the reading comprehension objectives. This list of questions can serve various purposes. It can stimulate a motivated reading at home, prior to the DA materials live presentation in the classroom. At the same time, it aids the comprehension of the texts. It can also draw the students' attention to the major issues and ideas presented in the texts. It will also serve to prepare and assist the students' capacity for developing independent understanding of the meaning of DA texts and its critical skills. It is not, however, recommended that the teacher provide a simple summary or a statement of the real DA since that these two should be reserved for the end result. The teacher should allow the students to enjoy the pleasure of discovery and learn how to comprehend and appreciate DA (Retrieved from http://www.Hello Friend.com).

Textual analysis and group work. A useful activity at this stage is allowing time to the students to think about major issues of the text. To initiate this process, the teacher can give the text to the student, to read at home, using the prepared glossary, and requiring the students to comment on basic issues of the text. The teacher can stimulate their imaginative power by inviting the students to write one or two paragraphs on the main ideas of the text or relate these ideas to their own real life experiences or even imagine themselves in 
circumstances suggested in the text. When working with motivated students, even two readings of the DA reading materials at home prior to its oral presentation in the classroom can be achieved. The first reading can accomplish comprehension objectives and the second one interpretation and critical analysis. It should be noted that the primary purpose of the use of DA materials and text in EFL/ESL curriculum is not just to expose our students to DA, but to involve them in a direct experience (Retrieved from http://About. com). In addition, the objectives of the language class should be carefully followed and implemented. Students' interest should be stimulated by activating their particular skills. They should be encouraged to read aloud the parts of the materials, supply summaries of the parts or whole of the text, and take part in group discussion concerning the important issues of the text. At this stage, students can move towards more mature critical analysis of the text. All these activities must be fully, creatively, and supportively supervised by teachers pleasurably (Kumaravadivelu, 2006).

Dixon and Krauss (1996) further suggested small group activities which can follow whole group work. These small group activities, focusing on a specific task, such as close reading of a significant part of the text, can encourage students to write relevant questions and later try to answer them.

Follow-up activities and further tasks. Re-reading of the DA reading materials also provides the students with an added advantage of establishing their previous knowledge about the text. To augment the effect of this re-reading activity, short writing assignments can be given to students to enable them to articulate and further develop their thoughts and the thematic meanings they have discovered through class discussion. Writing assignments based on the assigned DA enhance the students' involvement with the text and encourage them to think about, re-read, and further explore the text. Tierney and Shanahan (1991) confirmed that recent researches have indicated that writing tasks as a follow-up activity promote better learning and comprehension compared to reading alone; they lead to long-term recall of text content (Retrieved from http:// About. com).

Indeed, students should be able to carry an interaction with the DA beyond the oral class discussion to develop their language skills effectively. A more useful task would be to require the students to prepare creative, relevant DA comprehension materials and written responses and reaction reports. This opportunity allows the students to express their independent attitudes and opinions about the significant issues of DA. Tierney and Shanahan (1991) stated that writing tasks at this stage can take various forms. Students may be encouraged to keep a DA journal. Thus, they may be asked to write their personal attitudes about the tests in general. They may also be asked to comment on the outcome of the measurement and how they evaluate the ending. By the way, to get more benefits from DA reading comprehension materials, the following tips are also recommended and essential to apply to facilitate the below tasks (Tierney \& Shanahan, 1991).

(1) Create a DA literature classroom that enhances learning meaningfully with friendly framework of attitudes and values;

(2) Create and send a clear message about DA in target language. Students must know that mistakes are natural steps in learning and can point the way to success. They must know that they can improve their weaknesses. At this point, we should not give up on these kinds of students. We need to give them different homework and ask them to do it with other students using DA approach. We should never apply sarcasm, shame, and humiliation which are inappropriate ways of addressing the needs of unsuccessful or struggling learners. If we see our students show some signs of improvement, we must motivate them to continue. We know that the things which some students need to learn can be helpful to all students as well (Retrieved from http://www.finchpark.com/afe/w.htm). We should keep this point in our mind. This notion is proposed by 
Oliver and Bowler (2006): "Teachers teach students to learn the subject and learn how to learn";

(3) Teach famous illustrations of DA and its relation to ZPD that have genuine importance, and let your students know how and why. At this point, teachers must know that language awareness is conceptualized and it is defined as a person's sensitivity to conscious awareness of the nature of language and its role in human life (Donmall, 1985, p. 7). Vanlier (1995) explained it exactly as "an understanding of the human faculty of language and its role in thinking, learning, and social life”. The processes involved in understanding and producing utterances in an L2 are active and creative, and are central to L2 learning (Bygate, 1981). Therefore, it seems to be a need to better understand the following processes as the basic rules for developing appropriate steps for understanding. In order to get the best result of DA materials and texts, teachers must go through the following states: teaching for understanding:

(a) They teach information that has genuine importance, and let their students know why. They should make connections between life and school, and convey the significant and usefulness of what they are teaching Bailey (1990);

(b) They must organize what they are saying and have a flexible and motivated lesson plan (Bailey, 1990);

(4) Let the students see the definition, structure of DA in the course material they are learning. Emphasize the "why" and the "how". In order to make sure that the young learners understand the continuum of DA process, styles, and its strategies, make a list of some of the related materials and texts and assess them to see how much they learn. In this case, build students' self-motivation, risk taking and help them to develop intrinsic motivation Brown (2006);

(5) Teach in a very friendly manner and introduce and explain new vocabulary in context before students use it formally in text. The teachers should also try to put their emphasis on the definition as well as keywords which are related to DA;

(6) Apply multisensory teaching. The multisensory teaching technology relates to the different usages and applications of many different ways of teaching and learning DA strategies that promote learning in a wide variety of steps.

At this point, teachers should encourage students to participate in labs, do projects of field studies, role play, and perform demonstrations and simulations;

(7) Encourage students by giving them opportunity to verbalize, explain, summarize, express personal reactions, ask and answer questions and participate in discussion related to DA and ZPD;

(8) Use clear, simple and well organized visual references and teaching aids, if they are available, such as maps, charts, and diagrams. Make use of the blackboard, overheads, and if it is possible, use of computer. Teacher should highlight and put in an order the organized information by using different and attractive colorful board markers;

(9) Give special attention to recognize information and skills that are practiced to the point of automaticity as well as fluency with frequent regular assignments to practice these skills. We should recognize our student's capacity to do homework of the DA automaticity. We should tell our students in the early period of the semester that how we will evaluate their work and assess them for the whole semester (Retrieved from http://Education.com);

(10) Always offer flexible alternative tasks and involve students in the DA reading process. It is very useful if teachers always offer the learners multiple kinds of assignments and tests. They must permanently evaluate them with a range of ways to learn and to express their understanding. Teachers should give them the 
gift of time, de-emphasize the role of time and speed in assignment and test. They should also support DA learners who have appropriately documented a disability with students' services through providing modifications, such as alternative test environment, methods of evaluations, and time of tests. As Brindley (2002) pointed out "We need to find out more about the ways in which tests and other assessments are used. Only through the systematic exploration of such questions will it eventually be possible to improve the quality of teaching (DA approaches and its connection to ZPD) that language assessment can provide”.

\section{Conclusions}

In the long run, the teacher's role is a facilitator who guides the students as they draw inferences and form learning experiences through personal involvement with the text. The exposure of the students to DA and ZPD as ESL/EFL material can ensure that they enjoy, understand, and appreciate a life-like material while they are improving their essence of applying and enhancing sense of using test measurement proficiency. Thus, it will be to the overall benefit of the ESL/EFL learners if the instructors promote the use of DA as a tool to introduce, accompany, and supplement tried and basal teaching techniques. The power and impact found in a DA can offer the learners deeper meaning about the acquisition of language skills. Finally, DA reading comprehension and text invite students to engage in a more active and informed discussion of their involvement with the text and their own personal experiences relevant to the world of the text intellectually.

\section{References}

Ageyev, \& Miller, S. M. (Eds.). Cambridge: Cambridge University Press.

Mckinley, C. A. (1974). A study of ESL reading difficulties (Unpublished Master's thesis, University of California).

Arens, K. M., Swaffar, J. K., \& Byrnes, H. (1991). Reading for meaning: An integrated approach to language learning. Prentice Hall.

Bailey, K. M. (1990). The use of diary studies in teacher education programs. In J. C. Richards, \& D. Nunan (Eds.), Second language teaching education (pp. 215-240). CUP.

Bailey, K. (1996). Working for washback: A review of the washback concept in language testing. Language Testing, 13(3), 257-279.

Brindely, G. (1995). Competency-based assessment in second language programs. In Brindeley (Ed.), Language assessment in action. Sydney: New south Wales Adult.

Brindley, G. (2002). As contributor in "the Cambridge guide to teaching English to speakers of other languages". Cambridge University Press.

Brown, H. D. (2006). Principles of language learning and teaching. Addison Wesley Longman, Inc..

Bygate, M. (1981). Speaking. Oxford: Oxford University Press Migrant Education Service.

Dixon, \& Krauss, L. (1996). Vygotsky in the classroom: Mediated literacy instruction and assessment. White Plains, New York: Longman Publishers USA.

Donmall, B. G. (Ed.). (1985). Language awareness (NCL Papers and Report 6). London: Center for Information on Teaching and Research.

Gajduesk, L. (1979). Toward wider use of literature in ESL: Why and how. TESOL Quarterly, 22, 227-257.

Gorman, T. P. (1979). Teaching reading at the advanced level. In M. Celce-Murcia, \& L. McIntosh (Eds.), Teaching English as a second language (pp. 203-220). Rowley, M. A.: Newbury House.

Knutson, E. M. (1993). Teaching whole texts: Literature and foreign language reading instruction. The French Review, 67(1), 12-26.

Kouzlin, A., \& Grab, E. (2002). Dynamic assessment of EFL text comprehension of at-risk students. School Psychology International, 23, 112-127.

Kramsch, C., \& Kramsch. O. (2000). The avatars of literature in language study. The Modern Language Journal, 84(4), 553-573.

Kumaravadivelu, B. (2006). Understanding language teaching. Lawrence Erlbaum Associates Inc.. 
Lidz, C. S., \& Gindis, B. (2003). Dynamic assessment of the evolving cognitive functions in children. In Vygotsky's Educational Theory in Cultural Context. A. Kozulin, B. Gindis, V.S..

Nyikos, M., \& Hashimoto, R. (1997). Constructivist theory applied to collaborative learning in teacher education: In search of ZPD. The Modern Language Journal, 81(iv).

Oliver, \& Bowler. (2006). Learning to learn. London: Simmon and Schuster.

Richard, A., \& Raschio, R. A. (1991). Coursework for developing reading skills in a second language. Hispania, 74, $1139-1143$.

Poehner, M. E. (2008). A Vygotskian approach to understanding and promoting L2 development library of congress control.

Poehner, M. E., \& Vander Veer, R., \& Valsiner, J. (1991). Oxford: Blackwell.

Tierney, R. J., \& Shanahan, T. (1991). Research on the reading-writing relationship: Interactions, transactions, and outcomes. In R. Barr et al. (Eds.), Handbook of reading research (pp. 246-280). New York: Longman.

Van der Veer, R., \& Valsiner, J. (1991). Understanding Vygotsky. Oxford: Blackwell.

Vanlier, L. (1995). Introducing language awareness. London: Penguin.

Vygotsky, L. S. (1986). Thought and language. Cambridge MA: MIT.

Williams, M., \& Burden, R. L. (1994). The role of ... M. \& Burden, R. L. (1997). Psychology for language teachers: A social constructivist approach.

Woolfolk, A. (2004). Educational psychology. Boston Pearson. 